\title{
The role of ice nuclei recycling in the maintenance of cloud ice in Arctic mixed-phase stratocumulus
}

\author{
A. Solomon ${ }^{1,2}$, G. Feingold ${ }^{2}$, and M. D. Shupe ${ }^{1,2}$ \\ ${ }^{1}$ Cooperative Institute for Research in Environmental Sciences, University of Colorado Boulder, Boulder, Colorado, USA \\ ${ }^{2}$ Earth System Research Laboratory, National Oceanic and Atmospheric Administration, Boulder, Colorado, USA
}

Correspondence to: A. Solomon (amy.solomon@noaa.gov)

Received: 6 March 2015 - Published in Atmos. Chem. Phys. Discuss.: 21 April 2015

Revised: 13 September 2015 - Accepted: 14 September 2015 - Published: 25 September 2015

\begin{abstract}
This study investigates the maintenance of cloud ice production in Arctic mixed-phase stratocumulus in large eddy simulations that include a prognostic ice nuclei (IN) formulation and a diurnal cycle. Balances derived from a mixed-layer model and phase analyses are used to provide insight into buffering mechanisms that maintain ice in these cloud systems. We find that, for the case under investigation, IN recycling through subcloud sublimation considerably prolongs ice production over a multi-day integration. This effective source of IN to the cloud dominates over mixing sources from above or below the cloud-driven mixed layer. Competing feedbacks between dynamical mixing and recycling are found to slow the rate of ice lost from the mixed layer when a diurnal cycle is simulated. The results of this study have important implications for maintaining phase partitioning of cloud ice and liquid that determine the radiative forcing of Arctic mixed-phase clouds.
\end{abstract}

\section{Introduction}

Reliable climate projections require realistic simulations of Arctic cloud feedbacks. Of particular importance is accurately simulating Arctic mixed-phase stratocumuli (AMPS), which are ubiquitous and play an important role in regional climate due to their impact on the surface energy budget and atmospheric boundary layer structure through cloud-driven turbulence, radiative forcing, and precipitation (Curry and Ebert, 1992; Walsh and Chapman, 1998; Intrieri et al., 2002; Shupe and Intrieri, 2004; Sedlar et al., 2011; Persson, 2012). For example, Bennartz et al. (2012) showed that the extreme melt events observed at Summit, Greenland, in July 2012 would not have occurred without the surface radiative forcing produced by AMPS.

AMPS are characterized by a liquid cloud layer with ice crystals that precipitate from cloud base even at temperatures well below freezing (Hobbs and Rangno, 1998; Intrieri et al., 2002; McFarquhar et al., 2007). Radiative cooling near cloud top generates turbulence that maintains the liquid layer and forms an approximately well-mixed layer that extends as far as $500 \mathrm{~m}$ below cloud base. These cloud-driven mixed layers are frequently decoupled from the surface layer, limiting the impact of fluxes of heat, moisture, and aerosols on the cloud layer from below (Solomon et al., 2011; Shupe et al., 2013). However, unlike subtropical cloud-topped boundary layers where decoupling enhances cloud breakup by cutting the cloud system off from the surface source of moisture, decoupled AMPS can persist for extended periods of time due to weak precipitation fluxes out of the mixed layer and relatively moist air entrained into the cloud layer at cloud top (Tjernström et al., 2004; Solomon et al., 2011, 2014; Sedlar et al., 2012).

AMPS are challenging to model due to uncertainties in ice microphysical processes that determine phase partitioning between ice and radiatively important cloud liquid water (Sandvik et al., 2007; Tjernström et al., 2008; Klein et al., 2009, Karlsson and Svensson, 2011; Barton et al., 2012; Birch et al., 2012; de Boer et al., 2012), which drives turbulence that maintains the system. Phase partitioning depends upon the number, shape, and size of ice crystals, since these determine the efficiency of water vapor uptake by ice and hence the availability of water vapor for droplet formation (Chen and Lamb, 1994; Sheridan et al., 2009; Ervens et al., 2011; Hoose and Möhler, 2012). 
Since temperatures in AMPS are too warm for homogenous ice nucleation, ice must form through heterogeneous nucleation. Aerosols with properties to serve as seeds for heterogeneous ice crystal formation are referred to as ice nuclei (IN). A number of different aerosols such as mineral dust (Broadley et al., 2012; Kulkarni et al., 2012; Lüönd et al., 2010; Möhler et al., 2006; Pinti et al., 2012; Welti et al., 2009), soot (DeMott, 1990), sea salts (Wise et al., 2012), and bacteria (Kanji et al., 2011; Levin and Yankofsky, 1983) have been observed to act as IN, all of which nucleate at different temperatures and supersaturation ranges. In addition, observations indicate that nucleation properties are modified by aging and coating of aerosols (Möhler et al., 2005; Cziczo et al., 2009). Heterogeneous ice nucleation can occur by a number of modes: either in the presence of super-cooled droplets (contact and immersion freezing) or when vapor is deposited on IN (deposition freezing) (Pruppacher and Klett, 1997).

IN can be entrained into the cloud-driven mixed layer through turbulent mixing from above and/or below. Recent studies indicate that entrainment alone cannot account for observed ice crystal number concentration $\left(N_{\mathrm{ICE}}\right.$; Fridlind et al., 2012), motivating the use of diagnostic formulations for ice formation to produce model simulations of AMPS with realistic phase partitioning (Ovchinnikov et al., 2014). While this modeling strategy constrains $N_{\text {ICE }}$ to be close to the measured values, it eliminates the dynamicalmicrophysical feedbacks that regulate ice-liquid phase partitioning (Avramov et al., 2011).

Here we investigate a relatively unexplored source of ice production-recycling of ice nuclei in regions of ice subsaturation. AMPS frequently have ice-subsaturated air near the cloud-driven mixed-layer base where falling ice crystals can sublimate, leaving behind IN. This feedback loop is referred to from here on as "recycling". Recycling was found to be significant in large eddy simulations (LES) of a single-layer stratocumulus observed during the Department of Energy Atmospheric Radiation Measurement Program's Mixed-Phase Arctic Cloud Experiment (M-PACE; Verlinde et al., 2007; Fan et al., 2009). AMPS observed during M-PACE formed due to a cold-air outbreak, where large fluxes of heat and moisture over the open ocean forced turbulent roll clouds that were coupled to the surface layer. This coupling with the surface layer prevented the identification of the role of dynamics internal to the cloud-driven mixed layer in maintaining phase partitioning.

In this study we focus on the internal microphysics and dynamics of the cloud-driven mixed layer by investigating processes in an AMPS decoupled from surface sources of moisture, heat, and ice nuclei. We posit that recycling plays a significant role more generally since, for example, assuming an adiabatic vertical profile, a $650 \mathrm{~m}$ deep mixed layer with a cloud-top temperature of $-16^{\circ} \mathrm{C}$ requires a water vapor mixing ratio of at least $1.7 \mathrm{~g} \mathrm{~kg}^{-1}$ at mixed-layer base to be saturated with respect to ice, i.e., in order for recycling to be a negligible source of ice nuclei in the mixed layer. This value is typically only seen in the Arctic between May and September (Serreze et al., 2012), while persistent AMPS frequently occur outside of these months (Shupe et al., 2011).

We examine the role of IN recycling in maintaining ice production using large eddy simulations of a springtime decoupled AMPS. Three simulations are analyzed: "Control", with recycling turned on and shortwave radiation turned off (to compare with previous simulations of this case that use different IN formulations and shortwave radiation turned off); "NoRecycle", with IN recycling turned off to identify the impact of recycling on the cloud lifetime and phase partitioning; and "SW", with recycling and shortwave radiation turned on to identify the impact of realistic diurnal heating and cooling tendencies on the recycling process. This study builds on previous studies of this case, all of which exclude shortwave radiation (Avramov et al., 2011; Solomon et al., 2011, 2014), by including a prognostic equation for IN and a diurnal cycle. Within this modeling framework we investigate the relative roles of recycling and entrainment of IN in maintaining cloud ice production.

\section{Case description}

The case derives from observations of a persistent singlelayer Arctic mixed-phase stratocumulus cloud observed near Barrow, Alaska, on 8 April 2008 during the Indirect and Semi-Direct Aerosol Campaign (McFarquhar et al., 2011; see Fig. 1). The adjacent Beaufort Sea was generally ice covered during this time, with significant areas of open water observed east of Barrow. A $4 \mathrm{~K}$ temperature inversion with inversion base at $1.05 \mathrm{~km}$ was observed via a radiosonde at 17:34 UTC; static stability was near neutral within the mixed layer overlying a stable near-surface layer with static stability greater than $2 \mathrm{~K} \mathrm{~km}^{-1}$ below $500 \mathrm{~m}$. The water vapor mixing ratio, $q_{\mathrm{v}}$, decreased from $1.7 \mathrm{~g} \mathrm{~kg}^{-1}$ at the surface to $1.2 \mathrm{~g} \mathrm{~kg}^{-1}$ at cloud top, above which a secondary maximum of $1.6 \mathrm{~g} \mathrm{~kg}^{-1}$ was observed. Winds were east-southeasterly throughout the lowest $2 \mathrm{~km}$.

Measurements from ground-based, vertically pointing, $35 \mathrm{GHz}$ cloud radar, micropulse lidar, and dual-channel microwave radiometer at Barrow indicated a mixed-phase cloud layer starting at 08:00 UTC on 8 April 2008 with a cloud top at approximately $1.5 \mathrm{~km}$ that slowly descended to approximately $0.5 \mathrm{~km}$ over a $26 \mathrm{~h}$ period. At the time of the 17:34 sounding the cloud layer extended into the inversion by $100 \mathrm{~m}$ and had a cloud base and cloud top at $0.9 \mathrm{~km}$ and at $1.15 \mathrm{~km}$, respectively. Cloud ice water path (IWP), derived from cloud radar reflectivity measurements, varied from 20 to $120 \mathrm{~g} \mathrm{~m}^{-2}$ within $10 \mathrm{~min}$ of the sounding, with an uncertainty of up to a factor of 2 (Shupe et al., 2006). Concurrently, liquid water path (LWP), derived from dual-channel microwave radiometer measurements, was $39-62 \mathrm{~g} \mathrm{~m}^{-2}$, with an uncertainty of $20-30 \mathrm{~g} \mathrm{~m}^{-2}$ (Turner et al., 2007). 


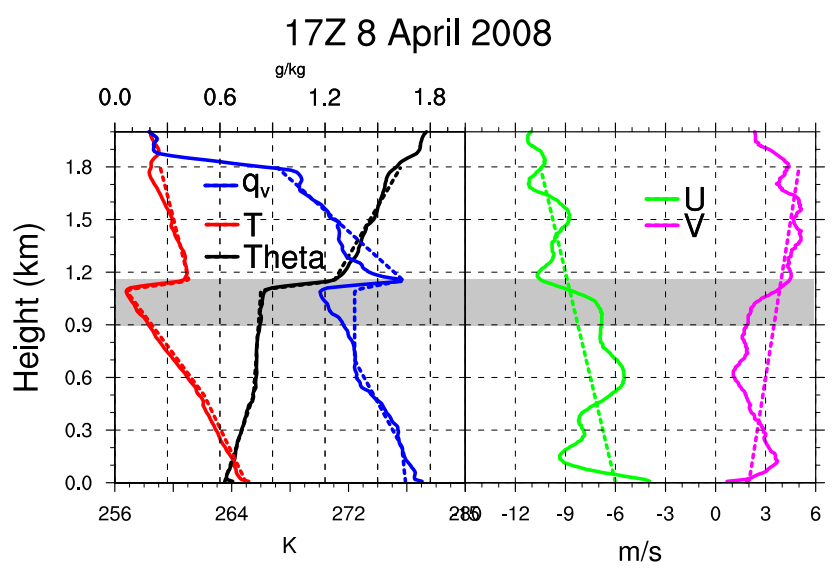

Figure 1. Sounding measured at 17:34 UTC 8 April 2008 at Barrow, Alaska $\left(71.338^{\circ} \mathrm{N}, 156.68^{\circ} \mathrm{W}\right)$. Left: water vapor mixing ratio $\left(q_{\mathrm{V}}\right)$, temperature $(T)$, and potential temperature (theta), in units of $\mathrm{g} \mathrm{kg}^{-1}$, kelvin, and kelvin respectively. Right: zonal wind $(U)$ and meridional wind $(V)$, in units of $\mathrm{ms}^{-1}$. Gray shading marks the extent of the cloud layer. The dashed lines show the initial profiles used in the WRFLES experiments. The dashed line overlying water vapor mixing ratio is the initial profile for the total water mixing ratio.

Research flights were conducted by the National Research Council of Canada Convair-580 at 22:27-23:00 UTC on 8 April 2008 over the ocean northwest of Barrow (McFarquhar et al., 2011). Droplet concentrations measured by a Particle Measuring Systems forward-scattering spectrometer probe varied between 100 and $200 \mathrm{~cm}^{-3}$. Ice crystal number concentrations measured by Stratton Park Engineering Company 2D-S and Particle Measuring Systems 2D-P optical array probes for sizes larger than $100 \mathrm{~m}$ together averaged $0.4 \mathrm{~L}^{-1}$. IN concentrations measured with the Texas A\&M Continuous Flow Diffusion Chamber varied from 0.1 to above $20 \mathrm{~L}^{-1}$. Ice crystal habit estimated using the automated habit classification procedure of Korolev and Sussman (2000) indicated primarily dendritic crystal habits.

\section{Model description}

We use the large eddy simulation mode of the Advanced Research WRF model (WRFLES) version 3.3.1 (Yamaguchi and Feingold, 2012) with the National Center for Atmospheric Research Community Atmospheric Model longwave radiation package (Collins et al., 2004), RRTMG shortwave package (Iacono et al., 2008), the Morrison two-moment microphysical scheme (Morrison et al., 2009), and a 1.5-order turbulent kinetic energy prediction scheme (Skamarock et al., 2008). Surface fluxes are calculated using the modified MM5 similarity scheme which calculates surface exchange coefficients for heat, moisture, and momentum following Webb (1970) and uses Monin-Obukhov with Carlson-
Boland viscous sublayer and standard similarity functions following Paulson (1970) and Dyer and Hicks (1970).

All model runs are initialized with winds, temperature, and water vapor from the $17 \mathrm{Z} 8$ April 2008 sounding at Barrow, Alaska (see Fig. 1). Initial surface pressure is $1020 \mathrm{hPa}$. Divergence is assumed to be $2.5 \times 10^{-6} \mathrm{~s}^{-1}$ below the temperature inversion and zero above, giving a linear increase in large-scale subsidence from zero at the surface to $2.7 \mathrm{~mm} \mathrm{~s}^{-1}$ at the base of the initial inversion $(z=1.1 \mathrm{~km})$. This value for divergence was chosen so that the height of the temperature inversion at cloud top is steady. The divergence used in this study is smaller than the divergence used in the WRFLES study of the same case by Solomon et al. (2014) due to the reduced LWPs in this current study and therefore reduced turbulent entrainment that balances large-scale subsidence in a steady simulation.

All simulations are run on a domain of $3.2 \times 3.2 \times 1.8 \mathrm{~km}$ with a horizontal grid spacing of $50 \mathrm{~m}$ and vertical spacing of $10 \mathrm{~m}$. The domain has $65(x) \times 65(y) \times 180(z)$ grid points and is periodic in both the $x$ and $y$ directions. The top of the domain is at $1.8 \mathrm{~km}$, which is $0.7 \mathrm{~km}$ above cloud top in this case. The model time step is $0.75 \mathrm{~s}$. The structure of the cloud layer is insensitive to changes in resolution and domain size. For example, tests run for Solomon et al. (2014) demonstrated that increasing the vertical and horizontal resolutions by a factor of 2 resulted in an increase in LWP and IWP by 5 and $1 \%$, respectively, while increasing the domain size by a factor of 2 in both the $x$ and $y$ directions results in an increase in LWP and IWP of less than $1 \%$.

Cloud droplets are activated using resolved and subgrid vertical motion (Morrison and Pinto, 2005) and a lognormal aerosol size distribution (assumed to be ammonium bisulfate and $30 \%$ insoluble by volume) to derive cloud condensation nuclei spectra following Abdul-Razzak and Ghan (2000). The aerosol accumulation mode is specified with concentrations of $165 \mathrm{~cm}^{-3}$, modal diameter of $0.2 \mu \mathrm{m}$, and geometric standard deviation of $1.4 \mathrm{~mm}$, based on in situ ISDAC measurements. In this formulation, IN and cloud condensation nuclei are treated as separate species.

Temperature and moisture profiles are nudged to the initial profiles in the top $400 \mathrm{~m}$ of the domain with a timescale of $1 \mathrm{~h}$. The model is initialized with winds, temperature, and water vapor similar to the Control integration from Solomon et al. (2014). Horizontal winds are nudged to the initial profiles at and above the initial inversion base with a timescale of $2 \mathrm{~h}$. Initial temperature and subgrid turbulent kinetic energy (TKE) are perturbed below the top of the mixed layer with pseudo-random fluctuations with amplitudes of $\pm 0.1 \mathrm{~K}$ and $0.1 \mathrm{~m}^{2} \mathrm{~s}^{-2}$, respectively. The liquid layer is allowed to form in the absence of ice during the first hour of the integration to prevent potential glaciation during spinup.

The cloud-driven mixed layer is defined as the region where the liquid-ice water static energy is approximately constant with height. We define the boundaries of the mixedlayer top and base to occur where the slopes of liquid-ice 
static energy exceed $7 \times 10^{-3}$ and $1 \times 10^{-3} \mathrm{~K} \mathrm{~m}^{-1}$, respectively. Cloud top and base are defined as the heights where cloud water mixing ratio, $q_{\mathrm{c}}$, is equal to $1 \times 10^{-4} \mathrm{~g} \mathrm{~kg}^{-1}$.

Nested Weather Research and Forecasting (WRF) model simulations of this case performed with an inner grid at LES resolution (Solomon et al., 2011) demonstrate that moisture is provided to the cloud system by a total water inversion at cloud top and that the mixed layer does not extend to the surface, i.e., the mixed layer is largely decoupled from surface sources of moisture. In addition, the nested simulations indicate that cloud liquid water, $q_{\mathrm{c}}$, is maintained within the temperature inversion by downgradient turbulent fluxes of $q_{\mathrm{v}}$ from above and direct condensation driven by radiative cooling. These processes cause at least $20 \%$ of $q_{\mathrm{c}}$ to extend into the temperature inversion.

WRFLES has been modified to include a prognostic equation for IN number concentration $\left(N_{\mathrm{IN}}\right)$,

$$
\frac{\partial N_{\mathrm{IN}}}{\partial t}+\mathrm{ADV}+\mathrm{DIFF}=\left.\frac{\delta N_{\mathrm{IN}}}{\delta t}\right|_{\text {activation }}+\left.\frac{\delta N_{\mathrm{IN}}}{\delta t}\right|_{\text {sublimation }},
$$

where ADV represents advection and DIFF represents turbulent diffusion. Activation is also referred to as nucleation of ice and sublimation is also referred to as recycling of IN.

Here we adopt an empirical approach by initializing $N_{\text {IN }}$ with an observationally based relationship expressing the number of available IN as a function of temperature in regions of water saturation (DeMott et al., 2010),

$N_{\mathrm{IN}}=F \cdot 0.117 \exp (-0.125 \cdot(T-273.2))$,

where $F$ is an empirically derived scale factor and $T$ is temperature in kelvin. Sixteen prognostic equations are integrated for $N_{\text {IN }}$ in equally spaced temperature intervals with nucleation thresholds between -20.2 and $-15.5^{\circ} \mathrm{C}$ (see Fig. 2). Therefore, additional IN become available for activation with decreasing temperature and as the cloud layer cools. IN number concentrations are initially specified using Eq. (2), such that the initial IN in bin $k$ is equal to the number of IN calculated by Eq. (2) at the threshold temperature $k+1$ minus that calculated at temperature $k$. After the initial time, $50 \%$ of the IN available in a bin nucleates if the in situ temperature is below the threshold temperature and the local conditions exceed water saturation. Therefore, initial $N_{\text {IN }}$ concentrations are a function of the nucleation threshold temperatures and are independent of the in situ temperature. The in situ temperature in regions of water saturation determines how many IN are activated. The activation of $50 \%$ of the available IN is used to take deviations from the empirical derivation into account; however results are insensitive to this parameter (not shown). Due to the pristine dendritic nature of the observed crystals, ice shattering and aggregation are neglected in the simulations and sublimation returns one $N_{\text {IN }}$ per crystal.

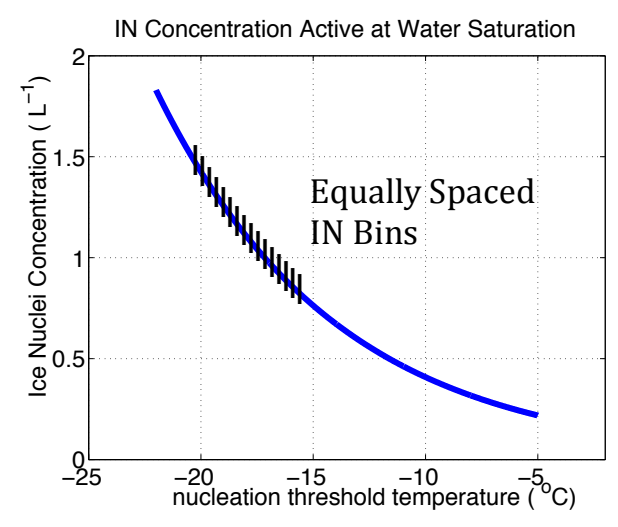

Figure 2. IN number concentration active at water saturation vs. temperature based on the empirical relationship derived in DeMott et al. (2010; blue line) used to initialize IN number concentration in each bin. Black vertical lines indicate threshold temperatures for nucleation in the 16 IN bins. Note that additional IN become available for nucleation at colder temperatures, such that, for example, at $-20.2{ }^{\circ} \mathrm{C}$ (the coldest temperature in the Control simulation) the total number of IN available for activation is $\sim 1.5 \mathrm{~L}^{-1}$.

$N_{\text {IN }}$ (in units of $\mathrm{L}^{-1}$ ) integrated over the domain in each temperature bin $k$ at time $t$ is equal to

$\bar{N}_{\mathrm{IN}}(k, t)=\iiint N_{\mathrm{IN}}(x, y, z, k, t) \mathrm{d} x \mathrm{~d} y \mathrm{~d} z$.

Upon sublimation, the modification of activation thresholds that can occur for previously nucleated IN, i.e., preactivation (Roberts and Hallett, 1967), is not considered and $N_{\mathrm{IN}}$ are returned to each bin $k$ with weighting

$W_{k}=\left[\bar{N}_{\mathrm{IN}}(k, 0)-\bar{N}_{\mathrm{IN}}(k, t)\right] / \bar{N}_{\mathrm{IN}}(k, 0)$,

where $W_{k}$ is normalized such that $\sum W_{k}=1$. The $W_{k}$ are recalculated each time step. In this way, IN are recycled preferentially to each of the 16 temperature bins from which they originated (Feingold et al., 1996).

The factor $F$ in Eq. (2) is set to 4 for all simulations yielding an initial $N_{\text {IN }}$ summed over all bins at every grid point equal to $5.8 \mathrm{~L}^{-1}$ at $20.2{ }^{\circ} \mathrm{C}$, compared to $10 \mathrm{~L}^{-1}$ used in LES studies of the same case presented in Avramov et al. (2011). Using a discrete bin formulation to represent Eq. (2) and assigning the coldest bin to the coldest temperature reached by the Control simulation $\left(-20.2^{\circ} \mathrm{C}\right.$ ) results in $3.26 \mathrm{~L}^{-1}$ in the warmest bin and $0.23 \mathrm{~L}^{-1}$ additional IN that are available for nucleation in the coldest bin. Given the initial temperatures in the cloud layer, all IN from the first bin in the cloud layer nucleate. This causes an initial spike in cloud ice number concentration, which also causes a large precipitation flux out of the mixed layer. It takes approximately $6 \mathrm{~h}$ for the cloud layer to reach a quasi-equilibrium with steady cloud ice production. Supplementary integrations were done to test for robustness of the results presented in Sect. 4 by varying initial IN concentrations, i.e., the factor $F$ (shown in 


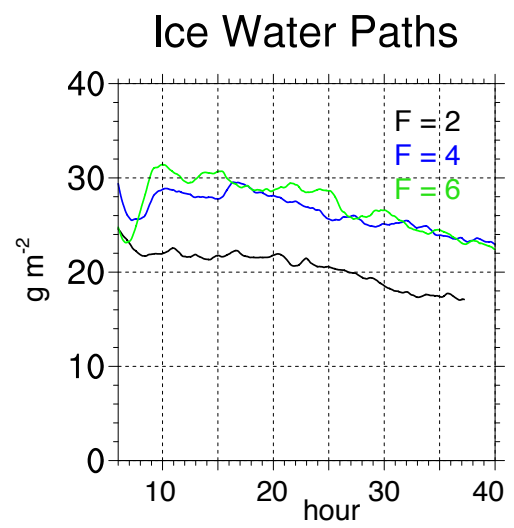

Figure 3. Sensitivity of ice water path to the parameter $F$ in Eq. (2). Note the similar ice water paths for $F=4$ and $F=6$ (total $N_{\text {IN }}$ initial values of 5.8 and $8.7 \mathrm{~L}^{-1}$, respectively).

Fig. 3), and by varying snow density and fall speeds (shown in Fig. 4). Figure 3 shows that the simulation maintains ice production when the initial $N_{\mathrm{IN}}$ is increased or decreased by $\sim 3 \mathrm{~L}^{-1}$ relative to the Control. Figure 4 shows that the simulations maintain quasi-steady ice and liquid water paths after an initial spinup but that the amount of ice produced is sensitive to the snow fall speed.

Crystal size distributions for averaged values of ice water mixing ratio and number concentration from the Control integration are shown in Fig. 5. These crystal size distributions are consistent with the Avramov et al. (2011) simulations of this case where crystal habits are assumed to be high-density pristine dendrites. The distribution shown in Fig. 5 underestimates the number of large (greater than $5 \mathrm{~mm}$ ) crystals as estimated by the 2D-S and 2D-P probes (see Avramov et al., 2011, for a detailed discussion of the measurements).

The Control integration is run with shortwave radiation turned off in order to compare with previous LES studies of this case (Avramov et al., 2011; Solomon et al., 2014). The results of the Control are compared to two additional simulations: one with IN recycling turned off (hereafter "NoRecycle") and one with recycling and shortwave radiation both turned on (hereafter "SW"). SW is used to investigate how the diurnal cycle impacts IN recycling and ice formation. All runs use the same setup except $\mathrm{SW}$, which has subsidence reduced by $30 \%$ to keep the mixed-layer top from lowering appreciably because of smaller LWPs. This allows for direct comparisons of mixed-layer structure and fluxes at the mixed-layer boundaries. The NoRecycle run is started from the Control run at hour 6 to prevent the two simulations from diverging due to spinup. The first $6 \mathrm{~h}$ of integration are not used in the analysis to allow for the spinup of cloud ice. Hours 6-40 are used for analysis of the Control and NoRecycle simulations and hours 16-76 are used for analysis of the SW simulation to allow for multiple diurnal cycles.
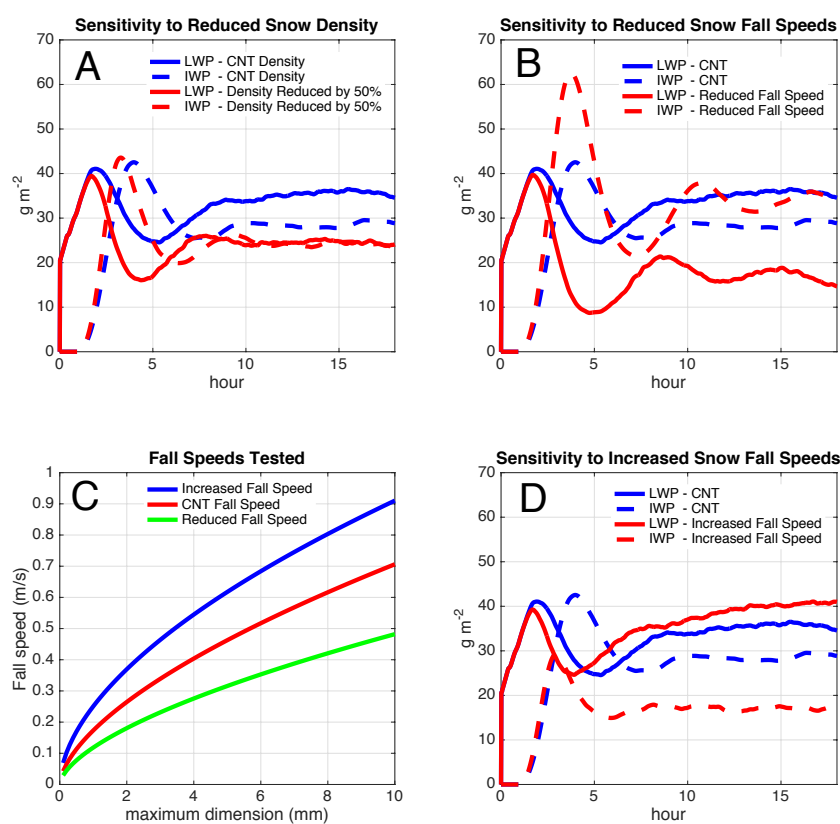

Figure 4. (a, b, d) Sensitivity of LWP and IWP to snow density and fall speeds. LWP shown with solid lines and IWP shown with dashed lines, in units of $\mathrm{g} \mathrm{m}^{-2}$. (c) Fall speeds used in sensitivity studies, in units of $\mathrm{m} \mathrm{s}^{-1}$. (a) Sensitivity to reducing snow density from 100 to $50 \mathrm{~kg} \mathrm{~m}^{-3}$ (red lines) using Control (CNT) fall speeds (red line in c). (b) Sensitivity to reducing snow fall speeds (green line in c) using Control snow density (red lines). (d) Sensitivity to increasing snow fall speeds (blue line in c) using Control snow density (red lines).

\section{Model results}

\subsection{Control integration}

In the quasi-steady Control integration, the mixed-layer depth is approximately $850 \mathrm{~m}$ and comprises a $375 \mathrm{~m}$ deep mixed-phase cloud layer (henceforth "the cloud layer"), extending above the mixed-layer top by $25 \mathrm{~m}$, and a $500 \mathrm{~m}$ subcloud layer below (Fig. 6). IN are produced by sublimation of ice crystals below the cloud layer, advected to the cloud layer by turbulence, and activated as ice crystals (Fig. 6). Ice that forms in the cloud layer is transported vertically by turbulence, precipitates to cloud base and below, and sublimates below the cloud layer. At the mixed-layer base, an increase in $N_{\text {ICE }}$ due to precipitation approximately balances a decrease in $N_{\text {ICE }}$ due to sublimation. These processes constitute a feedback through which ice production and IN recycling are closely related. This feedback between ice production and IN in the mixed layer is linked to dynamic-thermodynamic tendencies, which sustain a subsaturated subcloud layer because the decrease in relative humidity due to an upward turbulent vapor flux exceeds the increase due to sublimation.

The time evolution of horizontally averaged IN advection plus subsidence (Fig. 7a) shows that the majority of IN acti- 


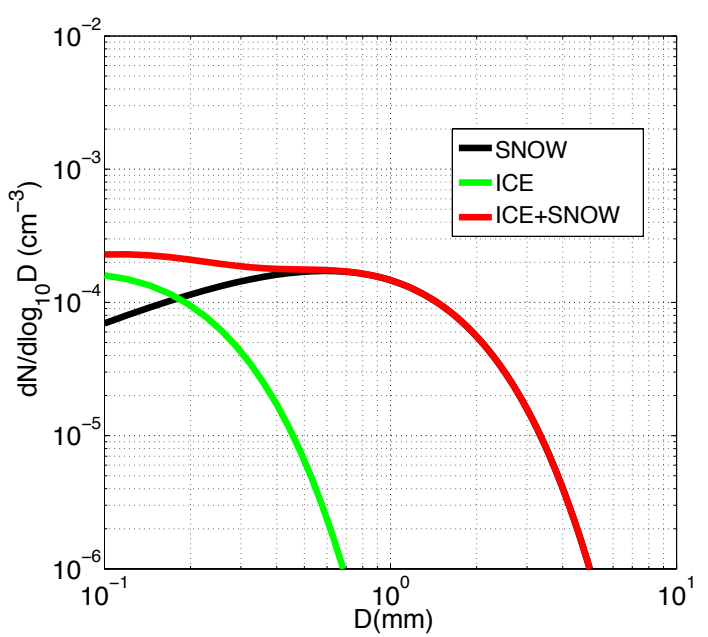

Figure 5. Simulated ice particle number size distributions using in-cloud mass and number concentrations. Ice water mixing ratio $=3 e-4 \mathrm{~g} \mathrm{~kg}^{-1}$, ice number concentration $=0.4 \mathrm{~L}^{-1}$, snow water mixing ratio $=2.4 e-2 \mathrm{~g} \mathrm{~kg}^{-1}$, and snow number concentration $=0.45 \mathrm{~L}^{-1}$.

vate at cloud base, which is a bit warmer than cloud top but is sufficiently cold to activate many of the IN. However, IN from bins with colder threshold temperatures are advected higher into the cloud, where they activate at their threshold temperature. A secondary maximum is seen at cloud top, where the coldest temperatures are found. Also, it is seen that IN are advected into the cloud layer at cloud top for the first $15-18 \mathrm{~h}$, but this source of IN decreases as IN in the upper entrainment zone are depleted. The turbulent mixing of snow and ice in the mixed-phase cloud layer is clearly seen in Fig. 7b, where ice plus snow number concentrations are well mixed in the cloud layer. Given the efficient mixing by the turbulent eddies, it is not possible to identify whether ice has nucleated at cloud base or cloud top from the ice number concentrations alone. Figure 7 also shows the time-height cross sections of horizontally averaged water vapor mixing ratio and relative humidity with respect to ice. These figures show that the continuous drying and cooling of the mixed layer results in continuous sublimation in the subcloud layer.

LWP and IWP remain steady until hour 16 of the simulation, and decrease slowly thereafter (solid lines in Fig. 8a). LWP and IWP magnitudes are within the observational estimates for this case. In addition, the cloud system is sustained over a multi-day period similar to measurements taken during ISDAC. Continuous cloud-top cooling causes the minimum horizontally averaged temperature (near cloud top) to decrease from -17.5 to $-20{ }^{\circ} \mathrm{C}$ from hour 10 to 40 (Fig. 8 b).

Over the $40 \mathrm{~h}$ integration, the mixed layer remains decoupled from the surface (Fig. 8c). However, this does not prevent the number concentration of ice crystals $\left(N_{\text {ICE }}\right)$ in the cloud layer from remaining relatively steady, decreasing from vertically integrated values of 372 to $365 \mathrm{~m} \mathrm{~L}^{-1}$

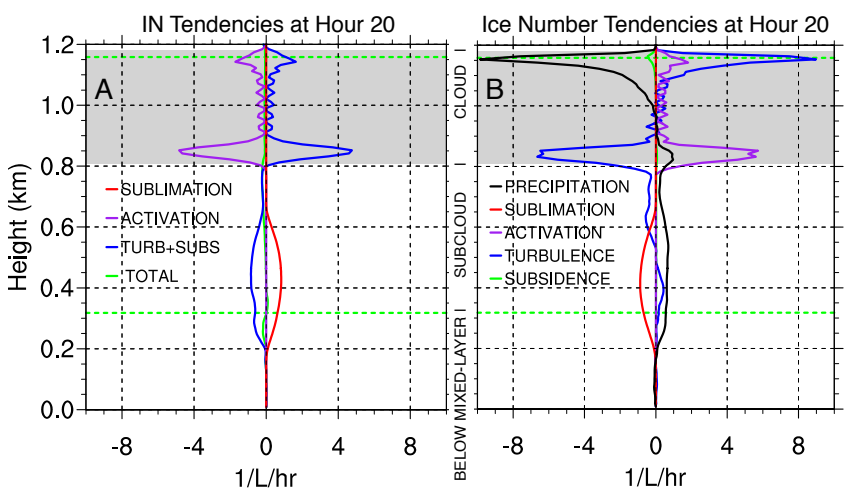

Figure 6. (a) $N_{\text {IN }}$ and (b) $N_{\text {ICE }}$ averaged over $0.5 \mathrm{~h}$ at hour 20 , in units of $\mathrm{L}^{-1} \mathrm{~h}^{-1}$. Gray shading indicates the extent of the cloud layer. Green dash lines indicate the top and bottom of the mixed layer.

(Fig. 8d; or, in terms of vertically averaged cloud layer values, 1.2 to $1.1 \mathrm{~L}^{-1}$ ). By contrast, while $N_{\mathrm{ICE}}$ is maintained in the cloud layer, $N_{\mathrm{IN}}$ in the subcloud layer decreases significantly from 2 to $0.2 \mathrm{~L}^{-1}$ over the same period. Therefore, even though more $N_{\mathrm{ICE}}$ are lost from the cloud than are activated (Fig. 9a), the relatively constant flux of IN into the cloud layer (Fig. 9b) allows $N_{\text {ICE }}$ in the cloud to decrease at a slower rate than $N_{\text {IN }}$ in the subcloud layer. The continuous loss of $N_{\text {IN }}$ in the subcloud layer is due to the IN flux into the cloud layer exceeding the $N_{\text {IN }}$ gained through sublimation and turbulent advection at mixed-layer base (Fig. 9b). This loss is not mitigated by entrainment at mixed-layer top, which is found to be negligible (Fig. 9c), consistent with Fridlind et al. (2012).

The feedback loops discussed above are illustrated by the conceptual diagram in Fig. 10, where any change to one link in the cycle leads to an increase or decrease in ice production. For example, a decrease in the turbulent advection of $N_{\text {IN }}$ into the cloud layer slows the activation of IN and reduces the precipitation flux into the subcloud layer, reducing sublimation and availability of IN below cloud base. Both dynamics and thermodynamics play a role in the buffering aspect of these feedback loops since, for example, the slowing of IN activation in the example above would lead to increased cloud liquid production, cloud-top radiative cooling, and enhanced turbulent mixing, which would lead to increased transport of IN into the cloud layer and therefore increased activation of IN.

\subsection{Impact of turning off recycling}

When IN recycling is turned off, all IN that activate are lost from the system. This results in a more rapid loss of IN, a decrease in IWP, and a rapid increase in LWP (Fig. 8a, d, dashed lines), in contrast to the measurements that show a steady liquid layer and consistent ice production. Increased cloud liquid water when recycling is turned off results in 

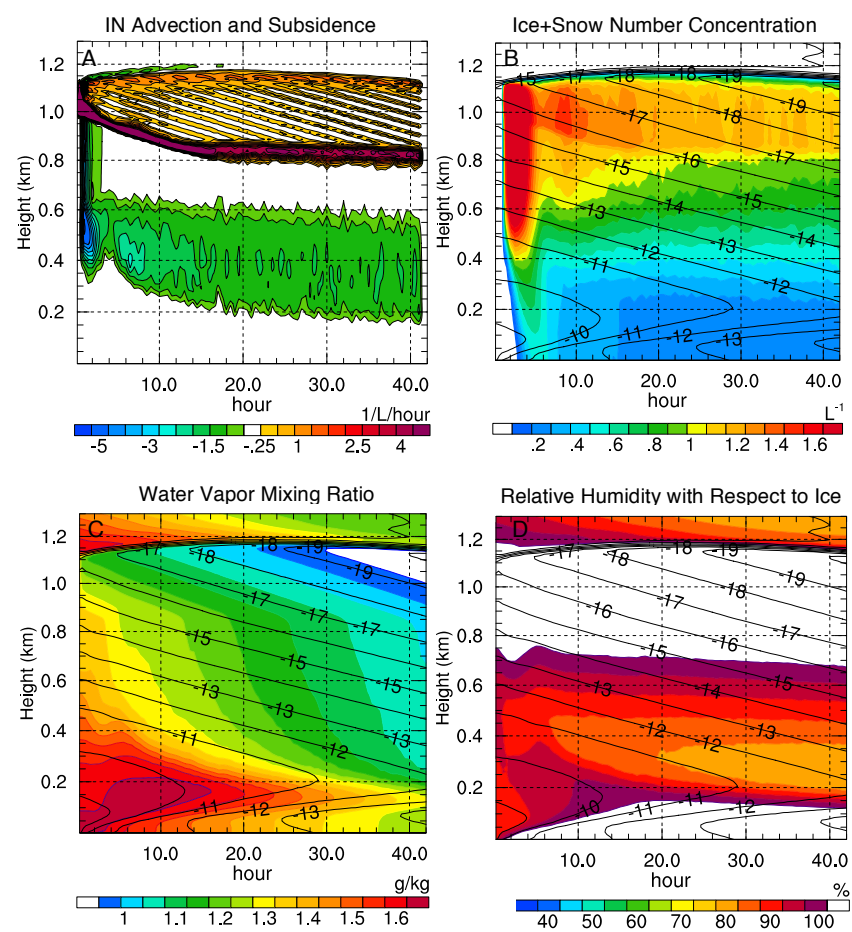

Figure 7. Time-height cross sections of horizontally averaged (a) IN advection plus subsidence, in units of $\mathrm{L}^{-1} \mathrm{~h}^{-1}$; (b) ice plus snow number concentration, in units of $\mathrm{L}^{-1}$; (c) water vapor mixing ratio, in units of $\mathrm{g} \mathrm{kg}^{-1}$; and (d) relative humidity with respect to ice, in units of percent, from CNT simulation. Temperature, in units of ${ }^{\circ} \mathrm{C}$, shown with black contour lines in $(\mathbf{b}, \mathbf{c}, \mathbf{d})$.

increased radiative cooling at cloud top, which causes the cloud-driven mixed layer to cool more rapidly (Fig. 8b). These results demonstrate the importance of IN recycling in regulating phase partitioning. The rapid increase in LWP increases cloud-generated turbulence via enhanced radiative cooling and increases the turbulent mixing of IN from the subcloud layer into the cloud layer, contributing to a more rapid depletion of IN relative to the Control integration. This process eventually becomes limited due to depletion of IN in the reservoir below (Fig. 9b). Due to the additional activation of IN as the cloud layer cools, ice production is maintained in the absence of recycling and the activation of IN in the cloud layer exceeds the upward IN flux at cloud base (Fig. 9a, b). However, the diminishing $N_{\text {IN }}$ in the subcloud layer limits IN activation and $N_{\text {ICE }}$ rapidly decreases in the cloud layer (Fig. 8d).

\subsection{Impact of diurnal cycle}

A diurnal cycle is added to the Control simulation in order to investigate how the feedback loops identified in the Control and NoRecycle runs are modified with realistic transient heating and cooling tendencies due to variations in incoming shortwave radiation. A question that is addressed in this diurnal simulation is, to what extent is the continuous production
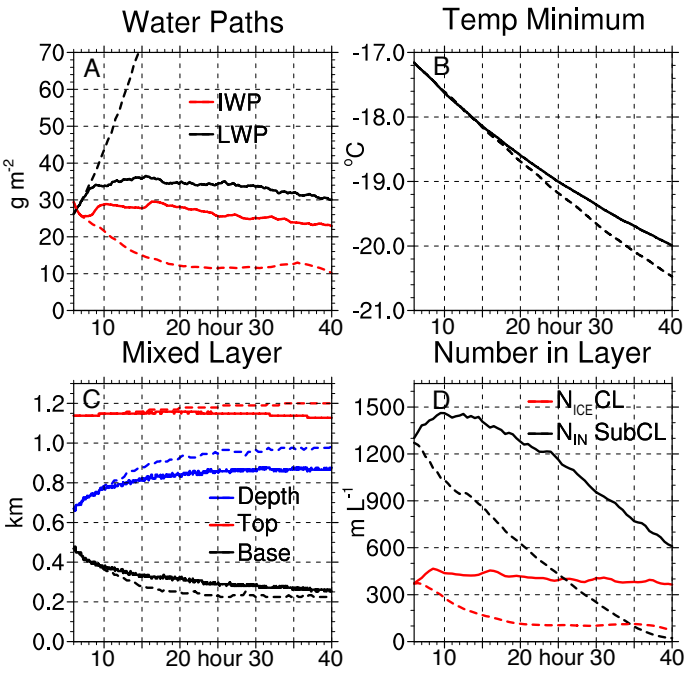

Figure 8. Control and NoRecycle time series for hours 6-40 (smoothed with $9 \mathrm{~min}$ running average). NoRecycle shown with dashed lines. (a) LWP (black) and IWP (red), in units of $\mathrm{g} \mathrm{m}^{-2}$. (b) Minimum horizontally averaged temperature in the column, in units of ${ }^{\circ} \mathrm{C}$. (c) Mixed-layer depth (blue), top height (red), and base height (black), in units of km. (d) $N_{\text {ICE }}$ integrated over cloud layer (referred to as CL, red) and $N_{\text {IN }}$ integrated over subcloud layer (referred to as SubCL, black), in units of $\mathrm{mL}^{-1}$.

of ice in the Control simulation due to the lack of incoming shortwave radiation, which may overestimate the cooling tendencies in the cloud layer, resulting in an overestimate of IN activation? In addition, we investigate whether allowing for a realistic diurnal cycle provides for additional negative or "buffering" feedbacks.

Adding a diurnal cycle to the Control simulation produces a diurnal peak in downwelling surface shortwave radiation of $510 \mathrm{~W} \mathrm{~m}^{-2}$ and $6 \mathrm{~h}$ of total darkness per day (Fig. 11b). As shortwave radiation increases, the net radiative cooling near cloud top diminishes, which decreases cloud-generated turbulence, decreasing LWP and cloud-layer thickness. In addition, it is seen that the peak daily LWP coincides with zero shortwave radiation when in-cloud turbulence and cloud thickness are largest (Fig. 11a). These values are on the low end but within the measurements for this ISDAC case.

Figure 11a and $\mathrm{b}$ show that LWP and IWP variability is predominantly driven by the diurnal cycle. However, IWP variability is seen to lag LWP by $3-4 \mathrm{~h}$, because as shortwave radiation decreases the cloud layer cools, which increases activation of IN, increasing $N_{\text {ICE }}$ and thus allowing more ice crystals to grow, which in turn increases IWP (Fig. 11a, b). Similar to the Control simulation, subcloud $N_{\text {IN }}$ decreases at a faster rate than cloud layer $N_{\text {ICE }}$ but allowing for the warming and cooling tendencies in the diurnal cycle results in cloud layer $N_{\text {ICE }}$ that decreases $40 \%$ more slowly than in the Control simulation (Fig. 11c). 


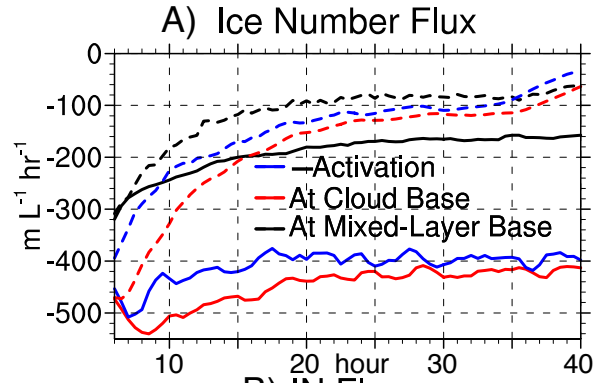

B) IN Flux

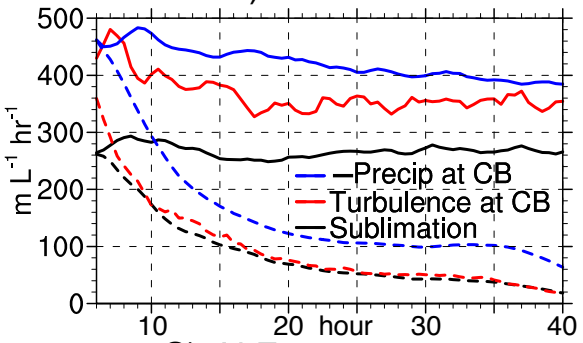

C) IN Entrainment

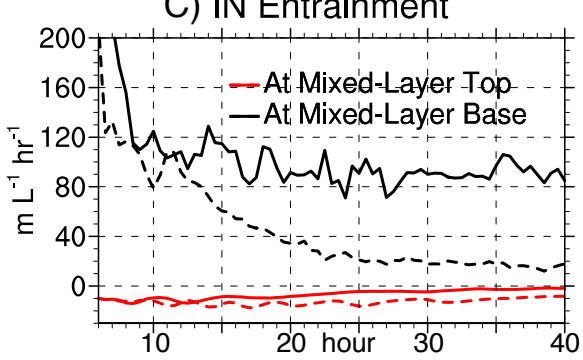

Figure 9. Horizontally averaged fluxes from the Control and NoRecycle integrations for hours 6-40 (smoothed with $90 \mathrm{~min}$ running average). NoRecycle shown with dashed lines. (a) $N_{\text {ICE }}$ flux at cloud base due to turbulence+subsidence+precipitation (red), mixed-layer base due to turbulence+subsidence+precipitation (black), and due to activation (multiplied by -1 , blue), in units of $\mathrm{mL}^{-1} \mathrm{~h}^{-1}$. (b) $N_{\text {IN }}$ flux at cloud base (indicated by CB in legend) due to turbulence (red), $N_{\text {IN }}$ flux due to sublimation (black), and precipitation of $N_{\text {ICE }}$ at cloud base (multiplied by -1 , blue), in units of $\mathrm{mL}^{-1} \mathrm{~h}^{-1}$. (c) $N_{\mathrm{IN}}$ entrainment at mixed-layer top (red) and base (black), in units of $\mathrm{mL}^{-1} \mathrm{~h}^{-1}$.

Precipitation and turbulent mixing of $N_{\text {ICE }}$ (hereafter turbulent mixing is referred to as " $T_{\mathrm{ICE}}$ ") at cloud base are out of phase by $10 \mathrm{~h}$ (Fig. 11d), with turbulence leading precipitation. When shortwave radiation is weak or absent, the increase in $N_{\text {ICE }}$ eventually becomes limited by a decreasing turbulent mixing of IN (" $T_{\mathrm{IN}}$ ") into the cloud layer from below, as recycling slows due to a decrease in $N_{\text {ICE }}$ flux from the cloud layer (Fig. 11d, f). When shortwave radiation is strong, reduction in IWP is limited by weaker precipitation losses, and attendant weaker sublimation and IN flux into the cloud layer (Fig. 11d, f). Entrainment of $N_{\mathrm{IN}}$ at the mixed-layer top is insignificant throughout the integration (Fig. 11e).

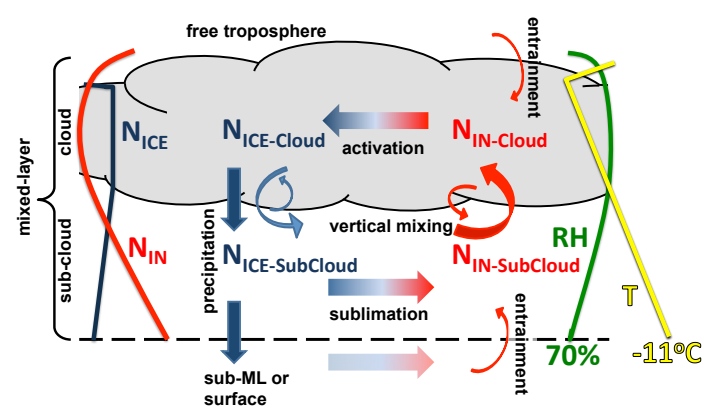

Figure 10. Schematic of feedback loops that maintain ice production and the phase partitioning between cloud liquid and ice in an

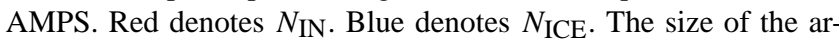
row indicates the relative magnitude of the flux. Vertical profiles of $N_{\text {ICE }}, N_{\text {IN }}$, relative humidity, and temperature shown with thin blue, red, green, and yellow lines, respectively.

\section{Analysis from a mixed-layer perspective}

The results discussed in Sect. 4 can be understood from balances in a well-mixed layer with sources/sinks at the upper and lower boundaries. Total particle concentration $\left(N_{\mathrm{IN}}+\right.$ $N_{\text {ICE }}$ ) is only changed by fluxes at the mixed-layer boundaries when recycling is allowed. These fluxes are entrainment of $N_{\mathrm{IN}}$ at mixed-layer top and turbulent mixing of both $N_{\mathrm{ICE}}$ and $N_{\mathrm{IN}}\left(T_{\mathrm{ICE}}\right.$ and $\left.T_{\mathrm{IN}}\right)$ and precipitation of $N_{\mathrm{ICE}}(P)$ at mixed-layer base. Since there are no sources and sinks of $N_{\text {IN }}+N_{\text {ICE }}$ within the mixed layer, the horizontally averaged $N_{\text {IN }}+N_{\text {ICE }}$ flux $(f(z))$ must vary linearly from mixedlayer base to mixed-layer top (Lilly, 1968; Bretherton and Wyant, 1997). If it is assumed that $f$ at the mixed-layer base is downward (assumed negative in this formulation) and $f$ at the mixed-layer top is negligible (robust assumptions for a scenario where ice is precipitating from the mixed layer and entrainment is weak), then

$f(z)=R \cdot \frac{H-z}{H-B}, \quad B \leq z \leq H$,

where $H$ is the mixed-layer height, $B$ is the mixed-layer base and $R$ is the total $N_{\mathrm{IN}}+N_{\mathrm{ICE}}$ flux at the mixed-layer base,

$R=\left.f\right|_{\text {Mixed-Layer Base }}=\left[P+T_{\mathrm{NI}}+T_{\mathrm{IN}}\right]_{\text {Mixed-Layer Base }}$,

and

$\left[T_{\mathrm{NI}}+T_{\mathrm{IN}}\right]_{\text {Cloud Base }} \approx[f-P]_{\text {Cloud Base }}$.

Since $f<0$, the turbulent flux of $N_{\mathrm{IN}}$ into the cloud layer plus the turbulent flux of $N_{\text {ICE }}$ into the subcloud layer is always less than precipitation of $N_{\text {ICE }}$ at cloud base. In addition, in a slowly evolving state where $\left.T_{\mathrm{IN}}\right|_{\text {Mixed-Layer Base }}>$ 0 , total IN flux due to sublimation in the mixed layer, $S$, can 

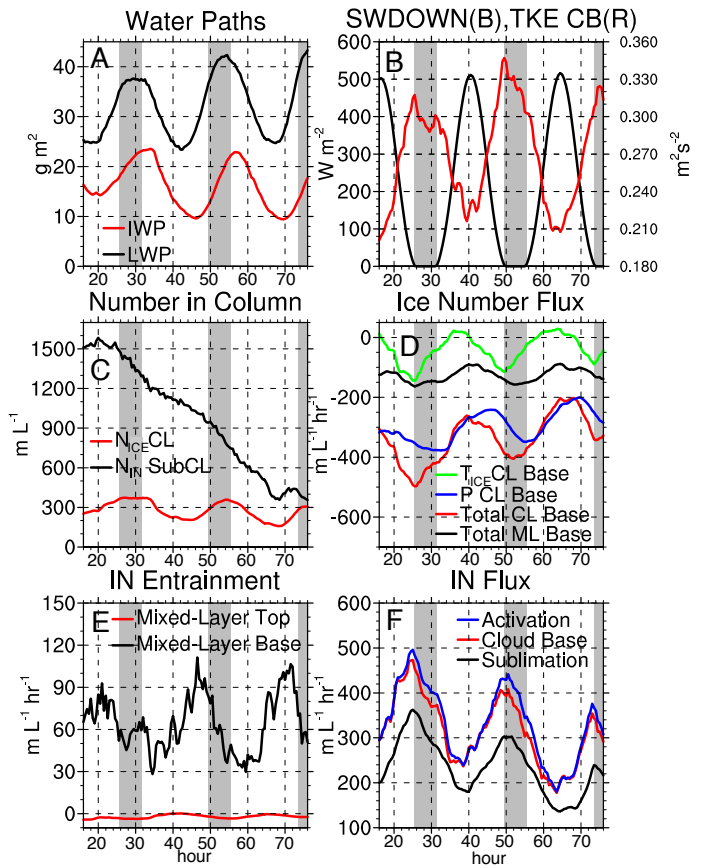

Figure 11. SW time series (see figure captions).

be written as

$$
\begin{aligned}
S & \approx\left[P+T_{\mathrm{NI}}\right]_{\text {Mixed-Layer Base }}-\left[P+T_{\mathrm{NI}}\right]_{\text {Cloud Base }}, \\
& \approx\left[f-T_{\mathrm{IN}}\right]_{\text {Mixed-Layer Base }}-\left[f-T_{\mathrm{IN}}\right]_{\text {Cloud Base }},
\end{aligned}
$$

and since $\left.f\right|_{\text {Mixed-Layer Base }}$ is downward and

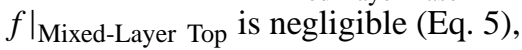

$S<\left.T_{\mathrm{IN}}\right|_{\text {Cloud Base }}-\left.T_{\mathrm{IN}}\right|_{\text {Mixed-Layer Base }}$

$<\left.T_{\mathrm{IN}}\right|_{\text {Cloud Base }}$.

Thus, in a well-mixed layer with an upward

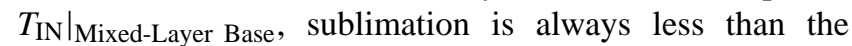
flux of $N_{\text {IN }}$ into the cloud layer.

Based on results from Control, precipitation of $N_{\text {ICE }}$ at cloud base is sufficient to balance the upward turbulent flux of $N_{\mathrm{IN}}$ (i.e., $\left|T_{\mathrm{IN}}\right| \gg\left|T_{\mathrm{ICE}}\right|$ at cloud base). Therefore, in a well-mixed layer with precipitation of $N_{\mathrm{ICE}}$ at the mixedlayer base that is larger in magnitude than an upward turbulent $N_{\text {IN }}$ flux at the mixed-layer base, and assuming negligible entrainment at the mixed-layer top,

$|P|_{\text {Cloud Base }}>\left.T_{\mathrm{IN}}\right|_{\text {Cloud Base }}>S$.

However, if all $N_{\text {ICE }}$ sublimate in the mixed layer and the upward turbulent flux of $N_{\mathrm{IN}}$ dominates at the mixed-layer base, then $f>0$ and

$\left.T_{\mathrm{IN}}\right|_{\text {Cloud Base }}>|P|_{\text {Cloud Base }}=S$,

resulting in a mixed layer that gains $N_{\mathrm{IN}}+N_{\mathrm{ICE}}$ over time and continuously increasing ice production in the cloud layer. In

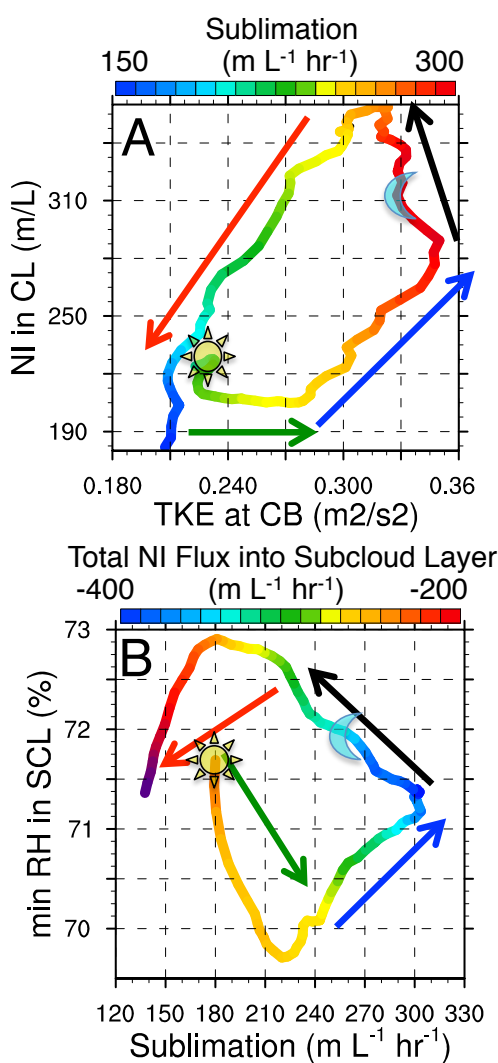

Figure 12. (a) Phase diagram of TKE at cloud base vs. $N_{\mathrm{ICE}}$ in the cloud layer starting at peak shortwave hour 40 , in units of $\mathrm{m} \mathrm{L}^{-1}$ and $\mathrm{mL}^{-1} \mathrm{~h}^{-1}$, respectively. Colors show sublimation in units of $\mathrm{mL}^{-1} \mathrm{~h}^{-1}$. (b) $24 \mathrm{~h}$ phase diagrams of sublimation vs. minimum relative humidity in the subcloud layer starting at peak shortwave hour 40 , in units of $\mathrm{mL}^{-1} \mathrm{~h}^{-1}$ and $\%$, respectively. Colors show total $N_{\text {ICE }}$ flux at cloud base, $\mathrm{m} \mathrm{L}^{-1} \mathrm{~h}^{-1}$. Hours $42-47,47-50$, 50-56, and 57-62 indicated with green, blue, black, red arrows, respectively. Minimum shortwave indicated with the moon symbol. Maximum shortwave indicated with the sun symbol.

the presence of shortwave radiation (i.e., in the SW simulation), $\left.T_{\text {IN }}\right|_{\text {Cloud Base }}$ is also greater than $|P|_{\text {Cloud Base }}$ after a period of weakened turbulence and weaker precipitation at the mixed-layer base, due to increased activation of $N_{\text {IN }}$ due to decreasing shortwave radiation.

If IN entrainment at the mixed-layer top is not negligible then $f(z)$ must be modified to include fluxes at the mixedlayer top and $|f|_{\text {Cloud Base }}$ will increase. If $|f|_{\text {Cloud Base }}$ increases such that $f_{\text {Cloud Base }}<P_{\text {Mixed-Layer Base, }}$, then sublimation will exceed $\left.T_{\mathrm{IN}}\right|_{\text {Cloud Base }}$.

This mixed-layer analysis provides a framework to understand the results presented in Sect. 4. Specifically, sublimation being less than the turbulent flux of IN is seen to be a property of a well-mixed layer where the total flux at mixedlayer base is downward and the total flux at the mixed-layer top is negligible. In the case where the mixed layer is saturated with respect to ice, sublimation is equal to zero and the 
turbulent flux of IN at the mixed-layer base is less that the turbulent flux of IN at the cloud base, reducing the flux of IN into the cloud layer. The relationships outlined in this section are appropriate for any AMPS with weak entrainment at cloud top, weak large-scale advective fluxes, and net downward fluxes at the mixed-layer base.

\section{Analysis of buffered feedbacks in SW}

Phase diagrams highlight the processes involved in ice production when a diurnal cycle is allowed (following the arrows from green to blue to black to red in Fig. 12a, b). When incoming shortwave radiation is a maximum, recycling (sublimation) is seen to be at a minimum. This is counterintuitive since subcloud relative humidity is low at this time, which would be expected to produce increased sublimation. However, due to weak turbulent mixing between the cloud and subcloud layers, the net $N_{\text {ICE }}$ flux into the subcloud layer is weak, resulting in weak sublimation and recycling. This situation is reversed as shortwave radiation decreases, since increased cloud-top cooling increases cloud-driven turbulent mixing, which allows recycling to increase in the regions of reduced subcloud relative humidity. As is seen in the conceptual diagram (Fig. 10), this then leads to an increased $N_{\text {ICE }}$ flux into the subcloud layer (green arrows, Fig. 12). However, $N_{\text {ICE }}$ in the cloud layer does not begin to increase until activation in the cloud layer exceeds the flux of $N_{\text {ICE }}$ into the subcloud layer (green arrows). This cycle is further amplified as shortwave radiation decreases, namely decreased shortwave radiation increases cloud-driven turbulence, increasing the flux of IN into the cloud layer, increasing the activation of IN, which increases $N_{\text {ICE }}$ in the cloud layer and the $N_{\text {ICE }}$ flux from the cloud layer into the subcloud layer (blue arrows).

When incoming shortwave radiation is a minimum, more $N_{\text {IN }}$ are activated because the cloud layer cools. However, again we see that $N_{\text {ICE }}$ tendencies due to thermodynamics are buffered by the slowing of turbulence-driven feedbacks due to a thickening of the cloud layer. Thus, a net increase in $N_{\text {ICE }}$ in the cloud layer, commensurate with an increased IWP and precipitation (black arrows), is buffered by a decrease in the downward turbulent mixing of $N_{\mathrm{ICE}}$, which reduces recycling, slowing the feedback loop (see Fig. 10). During the morning hours, as the cloud layer warms and thins and ice activation becomes less efficient, turbulence continues to decline, slowing the recycling feedback process to the point where limited IN fluxes to the cloud layer inhibit ice production and $N_{\text {ICE }}$ declines (red arrows).

\section{Summary}

We have demonstrated that sustained recycling of IN through a drying subcloud layer and additional activation of $N_{\text {IN }}$ due to a cooling cloud layer are sufficient to maintain ice produc- tion and that these processes regulate liquid production over multiple days in a decoupled AMPS.

This study provides an idealized framework to understand feedbacks between dynamics and microphysics that maintain phase partitioning in AMPS. In addition, we have shown that modulation of the cooling of the cloud layer and the humidity of the subcloud layer by the diurnal cycle buffers the mixedlayer system from a loss of particles and promotes the persistence of a mixed-phase cloud system. The results of this study provide insight into the mechanisms and feedbacks that may maintain cloud ice in AMPS even when entrainment of IN at the mixed-layer boundaries is weak. While the balance of these processes changes depending upon the specific conditions of the cloud layer, for example whether the cloud layer is coupled to the surface layer, the mechanisms detailed in this paper will manifest to some degree and therefore the current study provides a framework for understanding the role of recycling in maintaining phase partitioning in AMPS.

Author contributions. A. Solomon, G. Feingold, and M. D. Shupe conceived and designed the experiments. A. Solomon performed the simulations. A. Solomon, G. Feingold, and M. D. Shupe analyzed the model results and co-wrote the paper.

Acknowledgements. The authors acknowledge discussions with Alex Avramov, Chris Cox, Gijs de Boer, Barbara Ervens, and Ann Fridlind, and Takanobu Yamaguchi for developing the software to run WRF as a large eddy simulation. This research was supported by the Office of Science (BER), U.S. Department of Energy (DE-SC0011918), and the National Science Foundation (ARC-1023366).

Edited by: C. Hoose

\section{References}

Abdul-Razzak, H. and Ghan, S. J.: A parameterization of aerosol activation 2, Multiple aerosol types, J. Geophys. Res., 105, 68376844, 2000.

Avramov, A., Ackerman, A. S., Fridlind, A. M., van Diedenhoven, B., Botta, G., Aydin, K., Verlinde, J., Korolev, A. V., Strapp, J. W., McFarquhar, G. M., Jackson, R., Brooks, S. D., Glen, A., and Wolde, M.: Toward ice formation closure in Arctic mixedphase boundary layer clouds during ISDAC, J. Geophys. Res., 116, D00T08, doi:10.1029/2011JD015910, 2011.

Barton, N. P., Klein, S. A., Boyle, J. S., and Zhang, Y. Y.: Arctic synoptic regimes: Comparing domain wide Arctic cloud observations with CAM4 and CAM5 during similar dynamics, J. Geophys. Res., 117, D15205, doi:10.1029/2012JD017589, 2012.

Bennartz, R., Shupe, M., Turner, D., Walden, V., Steffen, K., Cox, C., Kulie, M. S., Miller, N., and Pettersen, C.: July 2012 Greenland melt extent enhanced by low-level liquid clouds, Nature, 496, 83-86, doi:10.1038/nature12002, 2012. 
Birch, C. E., Brooks, I. M., Tjernström, M., Shupe, M. D., Mauritsen, T., Sedlar, J., Lock, A. P., Earnshaw, P., Persson, P. O. G., Milton, S. F., and Leck, C.: Modelling atmospheric structure, cloud and their response to $\mathrm{CCN}$ in the central Arctic: ASCOS case studies, Atmos. Chem. Phys., 12, 3419-3435, doi:10.5194/acp-12-3419-2012, 2012.

Bretherton, C. S. and Wyant, M. C.: Moisture transport, lowertropospheric stability, and decoupling of cloud-topped boundary layers, J. Atmos. Sci., 54, 148-167, 1997.

Broadley, S. L., Murray, B. J., Herbert, R. J., Atkinson, J. D., Dobbie, S., Malkin, T. L., Condliffe, E., and Neve, L.: Immersion mode heterogeneous ice nucleation by an illite rich powder representative of atmospheric mineral dust, Atmos. Chem. Phys., 12, 287-307, doi:10.5194/acp-12-287-2012, 2012.

Chen, J.-P. and Lamb, D.: The theoretical basis for the parameterization of ice crystal habits: Growth by vapor deposition, J. Atmos. Sci., 51, 1206-1222, doi:10.1175/1520-0469(1994)051< 1206:TTBFTP> 2.0.CO;2, 1994.

Collins, W. D., Rasch, P. J., Boville, B. A., Hack, J. J., McCaa, J. R., Williamson, D. L., and Briegleb, B. P.: Description of the NCAR Community Atmosphere Model (CAM 3.0), NCAR Technical Note, NCAR/TN-464+STR, 226 pp., 2004.

Curry, J. and Ebert, E. E.: Annual cycle of radiation fluxes over the Arctic Ocean: Sensitivity to cloud optical properties, J. Climate, 5, 1267-1280, 1992.

Cziczo, D., Froyd, K., Gallavardin, S., Moehler, O., Benz, S., Saathoff, H., and Murphy, D.: Deactivation of ice nuclei due to atmospherically relevant surface coatings, Environ. Res. Lett., 4, 044013, doi:10.1088/1748-9326/4/4/044013, 2009.

de Boer, G., Chapman, W., Kay, J. E., Medeiros, B., Shupe, M. D., Vavrus, S., and Walsh, J.: A characterization of the present-day Arctic atmosphere in CCSM4, J. Climate, 25, 2676-2695, 2012.

DeMott, P. J.: An exploratory study of ice nucleation by soot aerosols, J. Appl. Meteorol., 29, 1072-1079, 1990.

DeMott, P. J., Prenni, A. J., Liu, X., Petters, M. D., Twohy, C. H., Richardson, M. S., Eidhammer, T., Kreidenweis, S. M., and Rogers, D. C.: Predicting global atmospheric ice nuclei distributions and their impacts on climate, P. Natl. Acad. Sci. USA, 107, 11217-11222, doi:10.1073/pnas.0910818107, 2010.

Dyer, A. J. and Hicks, B. B.: Flux-gradient relationships in the constant flux layer, Q. J. Roy. Meteor. Soc., 96, 715-721, 1970.

Ervens, B., Feingold, G., Sulia, K., and Harrington, J.: The impact of microphysical parameters, ice nucleation mode, and habit growth on the ice/liquid partitioning in mixed-phase Arctic clouds, J. Geophys. Res., 116, D17205, doi:10.1029/2011JD015729, 2011.

Fan, J., Ovchinnikov, M., Comstock, J. M., McFarlane, S. A., and Khain, A.: Ice formation in Arctic mixed-phase clouds: Insights from a 3-D cloud-resolving model with size-resolved aerosol and cloud microphysics, J. Geophys. Res., 114, D04205, doi:10.1029/2008JD010782, 2009.

Feingold, G., Kreidenweis, S. M., Stevens, B., and Cotton, W. R.: Numerical simulation of stratocumulus processing of cloud condensation nuclei through collision-coalescence, J. Geophys. Res., 101, 21391-21402, 1996.

Fridlind, A. M., van Diedenhoven, B., Ackerman, A. S., Avramov, A., Mrowiec, A., Morrison, H., Zuidema, P., and Shupe, M. D.: A FIRE-ACE/SHEBA case study of mixed-phase Arctic boundary-layer clouds: Entrainment rate limitations on rapid primary ice nucleation processes, J. Atmos. Sci., 69, 365-389, doi:10.1175/JAS-D-11-052.1, 2012.

Hobbs, P. V. and Rangno A. L.: Microstructure of low and middlelevel clouds over the Beaufort Sea, Q. J. Roy. Meteor. Soc., 124, 2035-2071, 1998.

Hoose, C. and Möhler, O.: Heterogeneous ice nucleation on atmospheric aerosols: a review of results from laboratory experiments, Atmos. Chem. Phys., 12, 9817-9854, doi:10.5194/acp-12-98172012, 2012.

Iacono, M. J., Delamere, J. S., Mlawer, E. J., Shephard, M. W., Clough, S. A., and Collins, W. D.: Radiative forcing by long-lived greenhouse gases: Calculations with the AER Radiative transfer models, J. Geophys. Res., 113, D13103, doi:10.1029/2008JD009944, 2008.

Intrieri, J. M., Fairall, C. W., Shupe, M. D., Persson, P. O. G., Andreas, E., Guest, P. S., and Moritz, R. E.: An annual cycle of Arctic surface cloud forcing at SHEBA, J. Geophys. Res., 107, C10, 8039, doi:10.1029/2000JC000439, 2002.

Kanji, Z. A., DeMott, P. J., Möhler, O., and Abbatt, J. P. D.: Results from the University of Toronto c ontinuous flow diffusion chamber at ICIS 2007: instrument intercomparison and ice onsets for different aerosol types, Atmos. Chem. Phys., 11, 31-41, doi:10.5194/acp-11-31-2011, 2011.

Karlsson, J. and Svensson, G.: The simulation of Arctic clouds and their influence on the winter surface temperature in present-day climate in the CMIP3 multi-model dataset, Clim. Dynam., 36, 623-635, 2011.

Klein, S. A., McCoy, R., Morrison, H., Ackerman, A., Avramov, A., de Boer, G., Chen, M., Cole, J., DelGenio, A. D., Falk, M., Foster, M., Fridlind, A., Golaz, J.-C., Hashino, T., Harrington, J., Hoose, C., Khairoutdinov, M., Larson, V., Liu, X., Luo, Y., McFarquhar, G., Menon, S., Neggers, R., Park, S., von Salzen, K., Schmidt, J. M., Sednev, I., Shipway, B., Shupe, M., Spangenberg, D., Sud, Y., Turner, D., Veron, D., Walker, G., Wang, Z., Wolf, A., Xie, S., Xu, K.-M., Yang, G., and Zhang, G.: Intercomparison of model simulations of mixed-phase clouds observed during the ARM Mixed-Phase Arctic Cloud Experiment, I: Single-layer cloud, Q. J. Roy. Meteor. Soc., 135, 979-1002, 2009.

Korolev, A. and Sussman, B.: A technique for habit classification of cloud particles, J. Atmos. Oceanic Technol., 17, 1048-1057, 2000.

Kulkarni, G., Fan, J., Comstock, J. M., Liu, X., and Ovchinnikov, M.: Laboratory measurements and model sensitivity studies of dust deposition ice nucleation, Atmos. Chem. Phys., 12, 72957308, doi:10.5194/acp-12-7295-2012, 2012.

Levin, Z. and Yankofsky, S.: Contact versus immersion freezing of freely suspended droplets by bacterial ice nuclei, J. Appl. Meteorol. Clim., 22, 1964-1966, 1983.

Lilly, D. K.: Models of cloud-topped mixed layers under a strong inversion, Q. J. Roy. Meteor. Soc., 94, 292-309, 1968.

Lüönd, F., Stetzer, O., Welti, A., and Lohmann, U.: Experimental study on ice nucleation ability of size selected kaolinite particles in the immersion mode, J. Geophys. Res., 115, D14201, doi:10.1029/2009JD012959, 2010.

McFarquhar, G. M., Zhang, G., Poellot, M. R., Kok, G. L., McCoy, R., Tooman, T., Fridlind, A., and Heymsfield, A. J.: Ice properties of single-layer stratocumulus during the Mixed-Phase Arctic Cloud Experiment: 1. Observations, J. Geophys. Res., 112, D24201, doi:10.1029/2007JD008633, 2007. 
McFarquhar, G. M., Ghan, S., Verlinde, J., Korolev, A., Strapp, J. W., Schmid, B., Tomlinson, J. M., Wolde, M., Brooks, S. D., Cziczo, D., Dubey, M. K., Fan, J., Flynn, C., Gultepe, I., Hubbe, J., Gilles, M. K., Laskin, A., Lawson, P., Leaitch, W. R., Liu, P., Liu, X., Lubin, D., Mazzoleni, C., Macdonald, A.-M., Moffet, R. C., Morrison, H., Ovchinnikov, M., Shupe, M. D., Turner, D. D., Xie, S., Zelenyuk, A., Bae, K., Freer, M., and Glen, A.: Indirect and Semi-Direct Aerosol Campaign (ISDAC): The Impact of Arctic Aerosols on Clouds, B. Am. Meteorol. Soc., 92, 183-201, doi:10.1175/2010BAMS2935.1, 2011.

Möhler, O., Bütuner, S., Linke, C., Schnaiter, M., Saathoff, H., Stetzer, O., Wagner, R., Krämer, M., Mangold, A., Ebert, V., and Schurath, U.: Effect of sulfuric acid coating on heterogeneous ice nucleation by soot aerosol particles, J. Geophys. Res., 110, D11210, doi:10.1029/2004JD005169, 2005.

Möhler, O., Field, P. R., Connolly, P., Benz, S., Saathoff, H., Schnaiter, M., Wagner, R., Cotton, R., Krämer, M., Mangold, A., and Heymsfield, A. J.: Efficiency of the deposition mode ice nucleation on mineral dust particles, Atmos. Chem. Phys., 6, 30073021, doi:10.5194/acp-6-3007-2006, 2006.

Morrison, H. and Pinto, J. O.: Mesoscale modeling of springtime Arctic mixed-phase stratiform clouds using a new two-moment bulk microphysics scheme, J. Atmos. Sci., 62, 3683-3704, 2005.

Morrison, H., Thompson, G., and Tatarskii, V.: Impact of cloud microphysics on the development of trailing stratiform precipitation in a simulated squall line: Comparison of oneand two-moment schemes, Mon. Wea. Rev., 137, 991-1007, doi:10.1175/2008MWR2556.1, 2009.

Ovchinnikov, M., Ackerman, A. S., Avramov, A., Cheng, A., Fan, J., Fridlind, A. M., Ghan, S., Harrington, J., Hoose, C., Korolev, A., McFarquhar, G. M., Morrison, H., Paukert, M., Savre, J., Shipway, B. J., Shupe, M. D., Solomon, A., and Sulia, K.: Intercomparison of large-eddy simulations of Arctic mixed-phase clouds: Importance of ice size distribution assumptions, J. Adv. Model. Earth Syst., 6, 223-48, doi:10.1002/2013MS000282, 2014.

Paulson, C. A.: The mathematical representation of wind speed and temperature profiles in the unstable atmospheric surface layer, J. Appl. Meteor., 9, 857-861, 1970.

Persson, P. O. G.: Onset and end of the summer melt season over sea ice: Thermal structure and surface energy perspective from SHEBA, Clim. Dynam., 39, 1349-1371, doi:10.1007/s00382011-1196-9, 2012.

Pinti, V., Marcolli, C., Zobrist, B., Hoyle, C. R., and Peter, T.: Ice nucleation efficiency of clay minerals in the immersion mode, Atmos. Chem. Phys., 12, 5859-5878, doi:10.5194/acp-12-58592012, 2012.

Pruppacher, H. and Klett, J.: Microphysics of clouds and precipitation. Kluwer Academic Publishers, 2nd edition, 954 pp., 1997.

Roberts, P. and Hallett, J.: A laboratory study of the ice nucleating properties of some mineral particulates, Q. J. R. Meteorol. Soc., 94, 25-34, 1967.

Sandvik, A., Biryulina, M., Kvamsto, N., Stamnes, J., and Stamnes, K.: Observed and simulated microphysical composition of Arctic clouds: Data properties and model validation, J. Geophys. Res. 112, D05205, doi:10.1029/2006JD007351, 2007.

Sedlar, J., Tjernström, M., Mauritsen, T., Shupe, M. D., Brooks, I. M., Persson, P. O. G., Birch, C. E., and C. Leck, C.: A transitioning Arctic surface energy budget: The impacts of solar zenith angle, surface albedo and cloud radiative forcing, Clim. Dynam., 37, 1643-1660, doi:10.1007/s00382-010-0937-5, 2011.

Sedlar, J., Shupe, M. D., and Tjernström, M.: On the relationship between thermodynamic structure, cloud top, and climate significance in the Arctic, J. Climate, 25, 2374-2393, 2012.

Serreze, M. C., Barrett, A. P., and Stroeve, J.: Recent changes in tropospheric water vapor over the Arctic as assessed from radiosondes and atmospheric reanalyses, J. Geophys. Res., 117, D10104, doi:10.1029/2011JD017421, 2012.

Sheridan, L. M., Harrington, J. Y., Lamb, D., and Sulia, K.: Influence of ice crystal aspect ratio on the evolution of ice size spectra during vapor depositional growth, J. Atmos. Sci., 66, 3732-3743, doi:10.1175/2009JAS3113.1, 2009.

Shupe, M. D and Intrieri, J. M.: Cloud radiative forcing of the Arctic surface: The influence of cloud properties, surface albedo, and solar zenith angle, J. Climate, 17, 616-628, 2004.

Shupe, M. D., Walden, V. P., Eloranta, E., Uttal, T., Campbell, J. R., Starkweather, S. M., and Shiobara, M.: Clouds at Arctic Atmospheric Observatories, Part I: Occurrence and macrophysical properties, J. Appl. Meteor. Clim., 50, 626-644, 2011.

Shupe, M. D, Matrosov, S. Y., and Uttal, T.: Arctic mixed phase cloud properties derived from surface-based sensors at SHEBA, J. Atmos. Sci., 63, 697-811, 2006.

Shupe, M. D., Persson, P. O. G., Brooks, I. M., Tjernström, M., Sedlar, J., Mauritsen, T., Sjogren, S., and Leck, C.: Cloud and boundary layer interactions over the Arctic sea ice in late summer, Atmos. Chem. Phys., 13, 9379-9399, doi:10.5194/acp-139379-2013, 2013.

Skamarock, W. C., Klemp, J. B., Dudhia, J., Gill, D. O., Barker, D. M., Duda, M. G., Huang, X.-Y., Wang, W., and Powers, J. G.: A description of the Advanced Research WRF version 3, NCAR Tech. Note NCAR/TN-475+STR, 113 pp., 2008.

Solomon, A., Shupe, M. D., Persson, P. O. G., and Morrison, H.: Moisture and dynamical interactions maintaining decoupled Arctic mixed-phase stratocumulus in the presence of a humidity inversion, Atmos. Chem. Phys., 11, 10127-10148, doi:10.5194/acp-11-10127-2011, 2011.

Solomon, A., Shupe, M. D., Persson, P. O. G., Morrison, H., Yamaguchi, T., Caldwell, P. M., and de Boer, G.: The sensitivity of springtime Arctic mixed-phase stratocumulus clouds to surface layer and cloud-top inversion layer moisture sources, J. Atmos. Sci., 71, 574-595, doi:10.1175/JAS-D-13-0179.1, 2014.

Tjernström, M., C. Leck, C., Persson, P. O. G., Jensen, M. L., Oncley, S. P., and Targino, A.: The summertime Arctic atmosphere: Meteorological measurements during the Arctic Ocean Experiment 2001, B. Am. Meteorol. Soc., 85, 1305-1321, 2004.

Tjernström, M., Sedlar, J., and Shupe, M. D.: How well do regional climate models reproduce radiation and clouds in the Arctic? An evaluation of ARCMIP simulations, J. Appl. Met. Clim., 47, 2405-2422, 2008.

Turner, D. D., Clough, S. A., Liljegren, J. C., Clothiaux, E. E., Cady-Pereira, K., and Gaustad, K. L.: Retrieving precipitable water vapor and liquid water path from Atmospheric Radiation Measurement (ARM) program's microwave radiometers, IEEE T. Geosci. Remote, 45, 3680-3690, 2007.

Verlinde, J., Harrington, J. Y., Yannuzzi, V. T., Avramov, A., Greenberg, S., Richardson, S. J., Bahrmann, C. P., McFarquhar, G. M., Zhang, G., Johnson, N., Poellot, M. R., Mather, J. H., Turner, D. D., Eloranta, E. W., Tobin, D. C., Holz, R., Zak, B. D., Ivey, 
M. D., Prenni, A. J., DeMott, P. J., Daniel, J. S., Kok, G. L., Sassen, K., Spangenberg, D., Minnis, P., Tooman, T. P., Shupe, M., Heymsfield, A. J., and Schofield, R.: The Mixed-Phase Arctic Cloud Experiment (M-PACE), B. Am. Meteorol. Soc., 88, 205-221, doi:10.1175/BAMS-88-2-205, 2007.

Walsh, J. E. and Chapman, W. L.: Arctic cloud-radiation temperature associations in observational data and atmospheric reanalyses, J. Climate, 11, 3030-3045, 1998.

Webb, E. K.: Profile relationships: The log-linear range, and extension to strong stability. Quart. J. Roy. Meteor. Soc., 96, 67-90, 1970.

Welti, A., Lüönd, F., Stetzer, O., and Lohmann, U.: Influence of particle size on the ice nucleating ability of mineral dusts, Atmos. Chem. Phys., 9, 6705-6715, doi:10.5194/acp-9-6705-2009, 2009.
Wise, M. E., Baustian, K. J., Koop, T., Freedman, M. A., Jensen, E. J., and Tolbert, M. A.: Depositional ice nucleation onto crystalline hydrated $\mathrm{NaCl}$ particles: a new mechanism for ice formation in the troposphere, Atmos. Chem. Phys., 12, 1121-1134, doi:10.5194/acp-12-1121-2012, 2012.

Yamaguchi, T. and Feingold, G.: Technical note: Large-eddy simulation of cloudy boundary layer with the Advanced Research WRF model, J. Adv. Model. Earth Syst., 4, M09003, doi:10.1029/2012MS000164, 2012. 